\title{
Transformation and Precipitation Processes in a Metal Substrate of Oxidized TiAl-Based Alloys
}

\author{
Joanna Małecka ${ }^{1}$ iD
}

Received: 7 May 2018 / Published online: 24 January 2019

(C) The Author(s) 2019

\begin{abstract}
This paper presents research results on the oxidation of $\gamma$-TiAl-based alloys collected over many years. The oxidation exposures were carried out in air at $875-975{ }^{\circ} \mathrm{C}$. Micro-areas close to the interface of the oxidation product-metallic substrate were analyzed. It was shown that the oxidation process takes place as a result of the outward diffusion of titanium ions, aluminum and alloying elements as well as the inward diffusion of oxygen and nitrogen, and the course of oxidation was also determined by the processes occurring in the metallic substrate.
\end{abstract}

Keywords Intermetallics · Oxidation · Diffusion

\section{Introduction}

Titanium alloys are distinguished by high strength and corrosion resistance. For this reason, they are widely used in aviation, chemical industry and medical engineering. However, its use in high temperatures is limited by poor oxidation resistance. Unlike most metals, titanium is characterized by the fact that both its low-temperature variant $\alpha$-Ti and the high-temperature variant $\beta$-Ti form terminal solid solutions with nitrogen and oxygen $[1,2]$. In both cases, the increase in the concentration of interstitial elements in the solid solution increases the transformation temperature $\alpha$ $\mathrm{Ti} \rightarrow \beta$-Ti, which means the extension of $\alpha$-Ti phase presence. The maximum oxygen solubility limit in $\alpha$-Ti is approximately 34 at. $\%$, and for nitrogen it is about 23 at.\%. In the $\beta$ phase, the solubility limit of oxygen and nitrogen is lower and, for example, at $1000{ }^{\circ} \mathrm{C}$ is, respectively, about $4 \%$ and about $2 \%$.

With technology advancement, a new group of titanium alloys was developed, displaying an improved high-temperature oxidation resistance, namely alloys based on intermediate phases (intermetallics). Such alloys have been the subject of many studies and partially overcame this disadvantage. The titanium aluminide

Joanna Małecka

j.malecka@po.opole.pl

1 Faculty of Mechanical Engineering, Opole University of Technology, Opole, Poland 
intermetallics are now regarded as viable choices for high-temperature applications, because of their high strength and low density [3, 4]. TiAl-intermetallic-based alloys may now be regarded as current generation structural materials, lighter than the conventional titanium alloys with the density lower than nickel-based superalloys [5]. However, the industrial application of these materials is still limited by their low ductility at room temperature, poor creep and oxidation resistance at elevated temperature [6]. Titanium with a low aluminum contents and $\alpha_{2}-\mathrm{Ti}_{3} \mathrm{Al}$ alloys are already widely used because of excellent mechanical properties. Therefore, titanium alloys with higher aluminum contents, such as $\mathrm{TiAl}$ and $\mathrm{TiAl}_{3}$ compounds, are still being developed for high-temperature applications [7]. Poor oxidation resistance currently limits the use of $\mathrm{TiAl}$ alloys above about $800^{\circ} \mathrm{C}$.

In Ti-Al alloys, aluminum in $\alpha$-Ti solid solution shows increasing solubility with increasing temperature, reaching the level of about 20 at. $\% \mathrm{Al}$ at $1000{ }^{\circ} \mathrm{C}$ [8-10]. With higher aluminum content, the intermetallic phases $\alpha_{2}-\mathrm{Ti}_{3} \mathrm{Al}$ and $\gamma$-TiAl are formed. In the intermetallic phase $\gamma$-TiAl, nitrogen has limited solubility, while in the $\alpha_{2}-\mathrm{Ti}_{3} \mathrm{Al}$ phase its solubility is much higher.

Many reports have discussed the oxidation behavior of $\gamma$-TiAl alloys [11-19]. An alloy's heat resistance depends primarily on the protective properties of the scale that forms in the course of oxidation. However, at high temperatures the scale formed on TiAl provides insufficient protection to the substrate material, resulting in its complete or partial destruction. Extensive studies have been conducted to improve the oxidation resistance of TiAl-based alloys [11-13], such as by alloying and for surface modification. Alloying with ternary, quaternary or more elements including $\mathrm{Nb}, \mathrm{Mo}, \mathrm{Cr}, \mathrm{Si}$, Ta $\mathrm{Zr}, \mathrm{V}$ and $\mathrm{W}$ was found to be an important method to improve the mechanical and oxidation properties of TiAl [7, 14-19].

During the oxidation of TiAl-based alloys simultaneously with the formation of the reaction product (oxide layer), the oxygen dissolution process takes place. In this case, two-directional diffusion in the reaction product happens, namely metal ions (alloy constituents) diffuse outward, while nitrogen and oxygen diffuse inward [20]. However, the differences resulting from the outward diffusion rate of the individual alloy components cause that the metallic substrate is poor in aluminum, which leads to the local disappearance of the $\gamma$-TiAl phase and the subsurface establishment of the $\alpha_{2}-\mathrm{Ti}_{3} \mathrm{Al}$ phase. At the same time, there is an increase in other phases which are characterized by high solubility of nitrogen and oxygen.

The research presented in this paper stems from a focused investigation of the $\gamma$-TiAl alloy and associated chemical composition of oxidation products. This work analyzes the transformation and precipitation processes taking place in the metallic substrate of the oxidized alloy based on the $\gamma$-TiAl phase matrix.

\section{Experimental Procedures}

High-temperature oxidation tests were carried out for a two-phase multi-component $\mathrm{Ti}-46 \mathrm{Al}-7 \mathrm{Nb}$ alloy of specific composition (in at.\%) in $\mathrm{Ti}-46 \mathrm{Al}-7 \mathrm{Nb}$ containing $46 \% \mathrm{Al}, 7 \% \mathrm{Nb}, 0.7 \% \mathrm{Cr}, 0.1 \% \mathrm{Si}$ and $0.2 \% \mathrm{Ni}$. Material in cylindrical form with a diameter of approx. $69 \mathrm{~mm}$ was purchased from Flowserve Corporation Titanium 
and Reactive Metals Foundry (USA). Samples were prepared for the tests with dimensions of $\approx 20 \times 15 \times 2 \mathrm{~mm}$. The parameters of the sample surface following polishing with abrasive papers to an 800 -grit finish were determined using the Hommel Tester 1000 profilometer with the LV15 measuring head. The roughness of the prepared surfaces was $\mathrm{Ra}=0.06 \mu \mathrm{m}$.

Oxidation in an air atmosphere was carried out using a temperature of $875^{\circ} \mathrm{C}$, $900{ }^{\circ} \mathrm{C}, 925^{\circ} \mathrm{C}, 950{ }^{\circ} \mathrm{C}$ and $975^{\circ} \mathrm{C}$. In the present study, the course of the oxidation kinetics of the alloy was not analyzed, but the processes and changes taking place in the metallic substrate were. For this purpose, a number of microstructural investigations were carried out with the analysis of chemical composition and phase composition tests. Microstructural investigations were carried out by scanning electron microscopy using a HITACHI S-4200 microscope and a Philips XL20 microscope. Secondary electrons (SE) and backscattered electrons (BSE) were used in the analyses.

Microanalysis of the chemical composition was made by means of EDS method using the Therm NORAN add-on with Six System coupled with the HITACHI S-3400 N microscope and the EDAX and WDX 400 analyzers coupled to a Philips XL20 microscope. Phase identification was made using X-ray diffraction. The tests were carried out on a JEX-7S diffractometer by JEOL, with a vertical focusing system. The source of radiation was a lamp with a copper anode, supplied with a constant voltage of $40 \mathrm{kV}$ at a current of $20 \mathrm{~mA}$. The length of Co- $\mathrm{K}_{\alpha}$ radiation used was $\lambda=0.154025 \mathrm{~nm}$. Phase identification was done using the PCSIWIN computer program using the JCPDS-International Center for Diffraction Data 2002 database. Phase composition was also examined on the X'Pert X-ray diffractometer by Philips. Co- $\mathrm{K}_{\alpha}$ cobalt lamp radiation was used with a crystalline monochrome before the detector. The measurements were taken in the angular range $2 \Theta=10-1500$. Subsequently, the measurement confrontation was made.

\section{Results}

The structure of the tested Ti-46Al-7Nb alloy can be described as duplex (Fig. 1), and it reveals the dendritic system with clear contrasts between the dendrite axes and interdendritic zones and phases.

When analyzing the surface and cross sections of the oxidized alloys, it was found that the resulting scale layer is always characterized by the same order of sublayers regardless of temperature. However, the growth of the scale increases the thickness of the oxide layer. Thus, on the outer surface of the oxidized alloy columnar crystallites are growing above the surface in different directions. In the temperature range between 875 and $925^{\circ} \mathrm{C}$, they have very small dimensions (Fig. 2). It can be seen that they do not form on the entire surface of the alloy but grow over a sublayer rich in $\mathrm{Al}_{2} \mathrm{O}_{3}$. The shape of these crystallites is identical to that observed by Król [20] on technical titanium and identified as an allotropic $\mathrm{TiO}_{2}$ variety called rutile. The observation of the outer surface of the oxidation products formed in the temperature range between 950 and $975{ }^{\circ} \mathrm{C}$ allows to determine that rutile columnar crystallites formed as a result of simultaneously occurring processes of the surface 


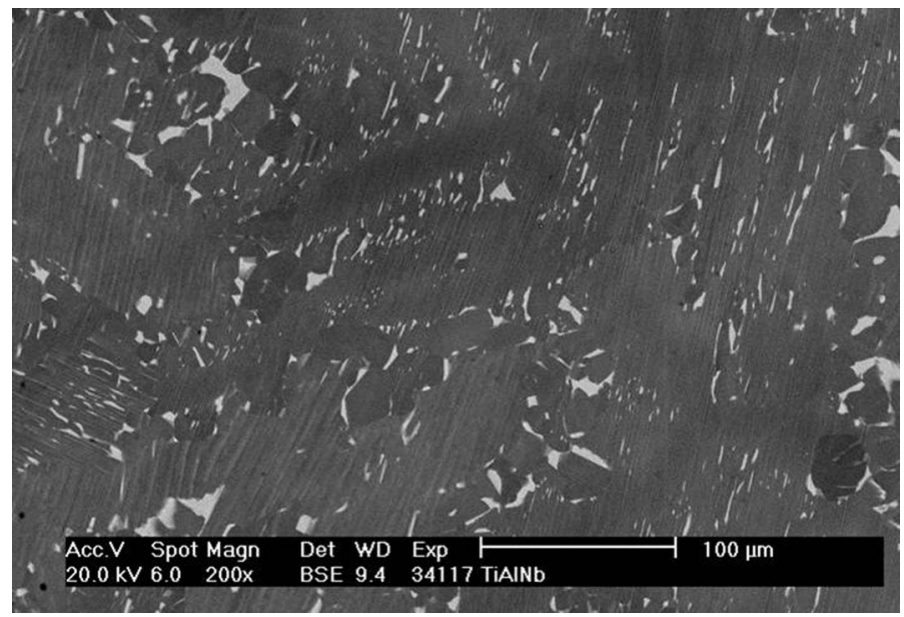

Fig. 1 Structure of the Ti-46Al-7Nb alloy

diffusion and the outward diffusion of titanium ions have larger sizes than after oxidation in $875-925^{\circ} \mathrm{C}$ (Fig. 2b). The formation of such rutile columnar crystallites as shown in Fig. 2 requires clarification. These crystallites are situated at different angles to each other and in relation to the surface from which they grow. This product is formed not only as a result of the outward diffusion of titanium ions, but also as a result of surface diffusion. Król [20] interpreted such crystallite growth based on the model presented by Jungling and Rapp [21]. The research by Rapp et al. [22, 23] using an HSESEM (hot-stage environmental scanning electron microscope) and recorded with video cameras showed that at a lower oxidation temperature, surface diffusion is the fastest process that leads to the formation of whiskers. A small contribution of the network diffusion causes their widening or increase in the perpendicular direction. As the temperature increases, the proportion of network diffusion becomes more and more significant, causing oxide growth to occur quickly over the entire surface of the grain, while at the dislocation, stress and surface energy are minimized by the inward growth of the pit. The observed crystallites are therefore formed with the interaction of both types of diffusion. This proves that through the product layer, both those rich in $\mathrm{Al}_{2} \mathrm{O}_{3}$ and those rich in $\mathrm{TiO}_{2}$, an outward transfer of titanium ions takes place. This proves the fact that sufficiently homogeneous $\mathrm{Al}_{2} \mathrm{O}_{3}$ sublayer, which could prevent diffusion processes and thus to visibly increase resistance to oxidation, has not been formed.

The cross sections of scale observed in BSE show that this external sublayer (rutile crystallites, Fig. 4a) does not fully cover the surface (Fig. 3), and another sublayer, which produces heterogeneous gray-black contrast in BSE, is locally in contact with the oxidant. The interface between this sublayer and the adjacent one is almost flat and does not contain structural crystalline macro-defects. The microanalysis of this sublayer (Fig. 4b) shows that Al dominates with a much smaller share of Ti. Therefore, it can be claimed that in this sublayer there is a dominance of aluminum oxides, although titanium oxides are also present, as 

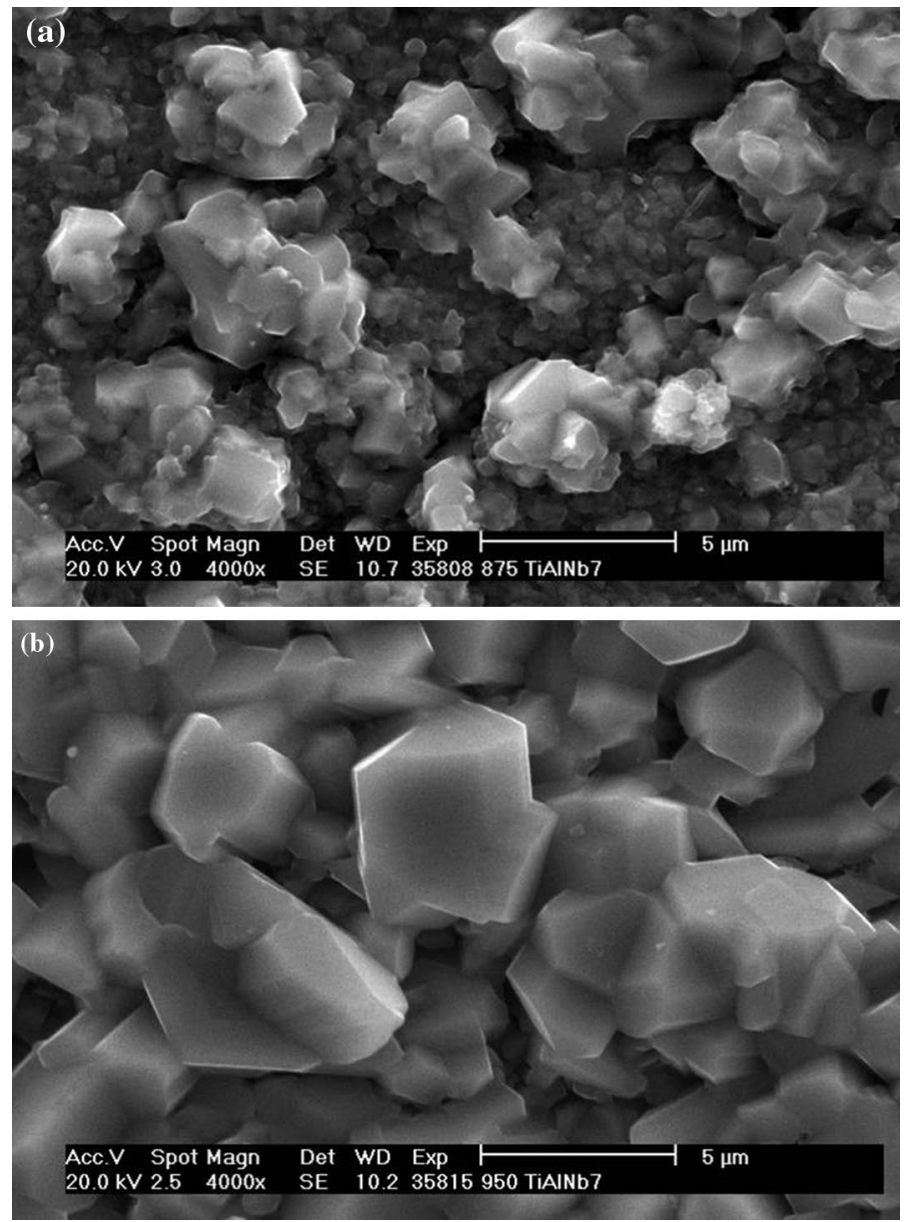

Fig. 2 Surface of Ti-46Al-7Nb alloy oxidized in air at temperature $875{ }^{\circ} \mathrm{C}$ (a) and $975{ }^{\circ} \mathrm{C}(\mathbf{b})$

well as niobium. The presence of the remaining elements $\mathrm{Nb}$ and $\mathrm{Ti}$ indicates that there is a cation flow toward this layer, so the outward diffusion takes place. Between these two sublayers there are visible voids displayed in BSE as black nano-areas (Fig. 3b). Another, third oxide sublayer stretches down to the interface with the metallic substrate. In comparison to the sublayers described previously, it has the largest thickness. In BSE this sublayer is light gray, but it also contains almost completely white and black areas. The latter are located near the interface with a metallic substrate. They are extremely small in size and formed in diffusion processes as a result of coalescence of vacancies. In the areas lying at the phase interface, these voids combine with each other causing local discontinuities. This changes the course of diffusion processes and can lead to local spalling. The effect of various gray shades in BSE informs about a different composition. Al oxides occur in this sublayer; however, Ti oxides are 

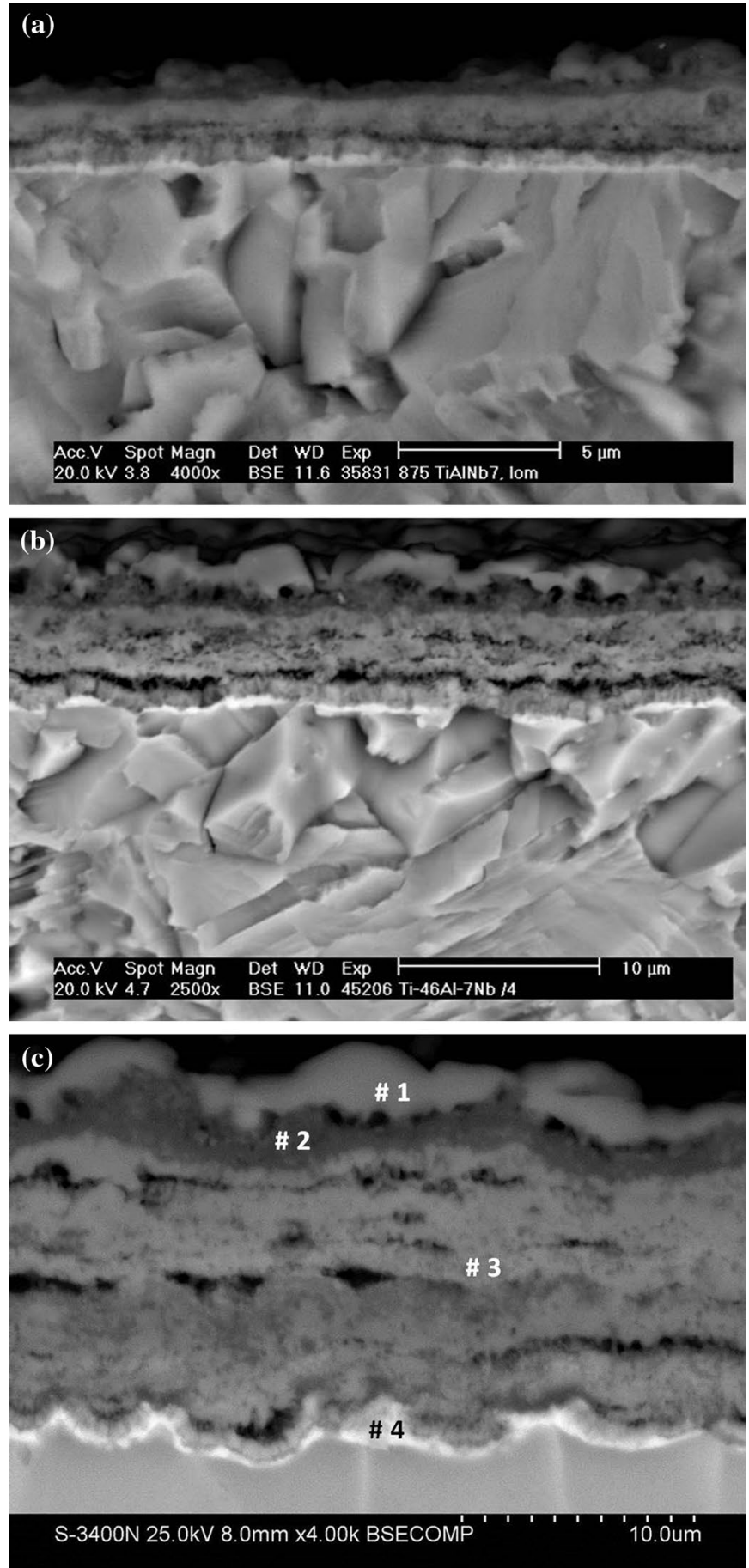

Fig. 3 Cross section of the scale formed on $\mathrm{Ti}-46 \mathrm{Al}-7 \mathrm{Nb}$ alloy after oxidation in air at $875{ }^{\circ} \mathrm{C}(\mathbf{a})$, $925{ }^{\circ} \mathrm{C}(\mathbf{b})$ and $950{ }^{\circ} \mathrm{C}(\mathbf{c})$ 


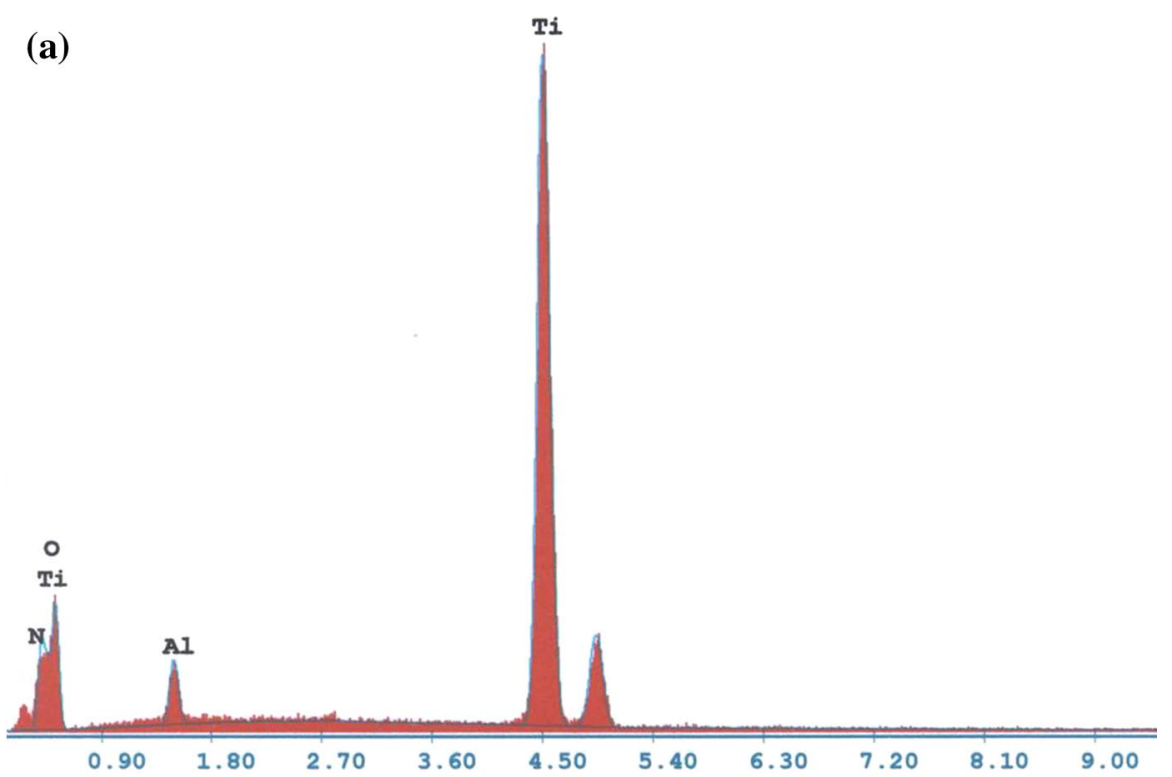

(b)

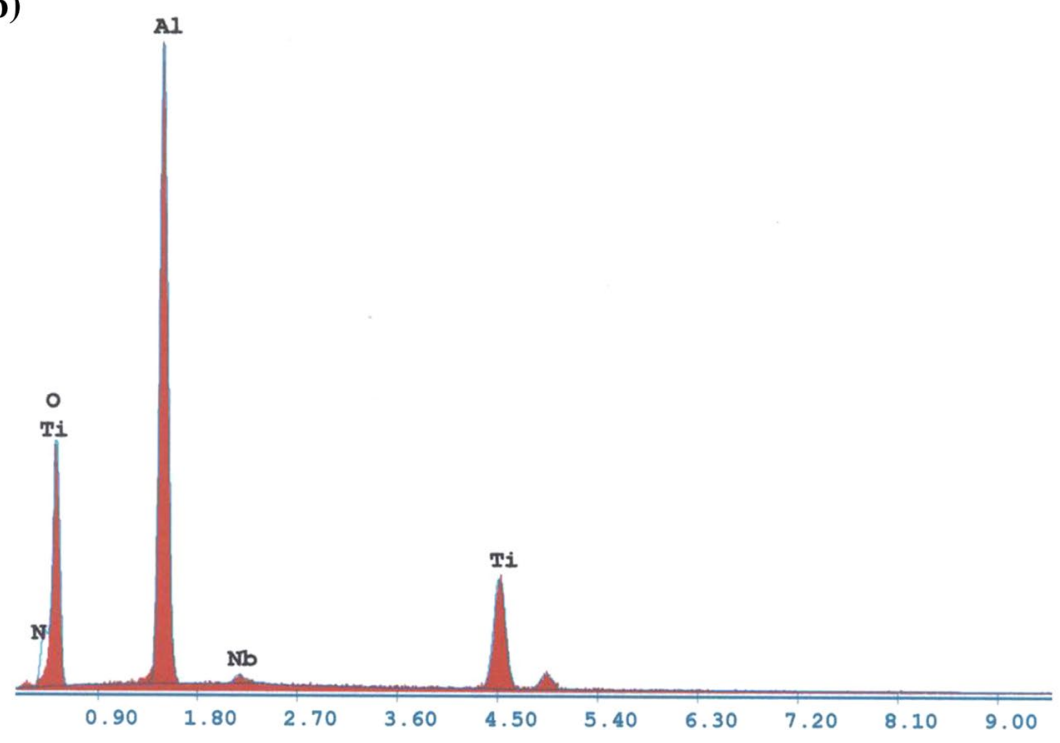

Fig. 4 EDS analysis results in point \# 1 (a), \# 2 (b), \# 3 (c), \# 4 (d) marked in Fig. 3c

the dominant ones. This is confirmed by analysis (Fig. 4c) in the area of this sublayer. Dark-gray micro-areas show higher Al concentrations, whereas lightgray areas show higher Ti concentrations. Generally, however, it can be concluded that the sublayer is dominated by titanium oxides hence the color of BSE is closer to the color of columnar crystallites of rutile. At the interface between 
(c)

Ti

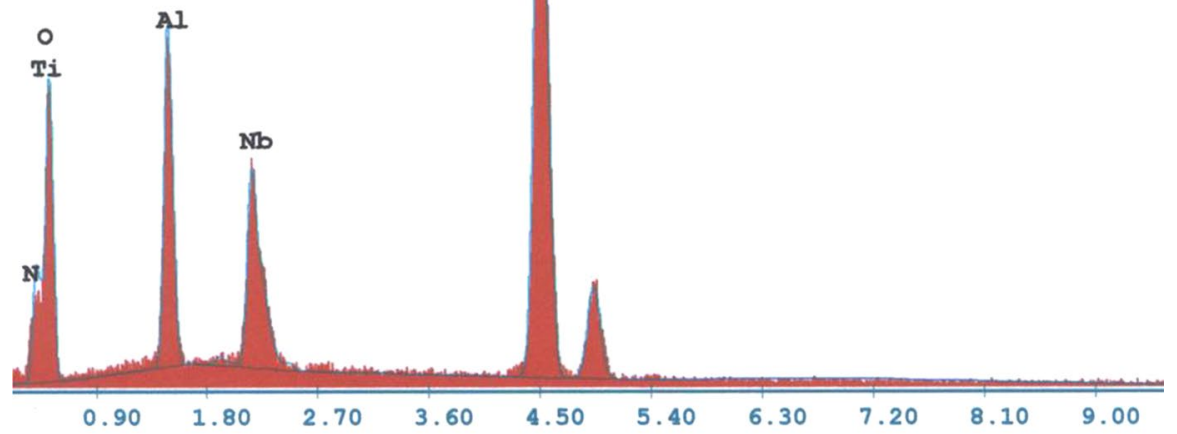

(d)

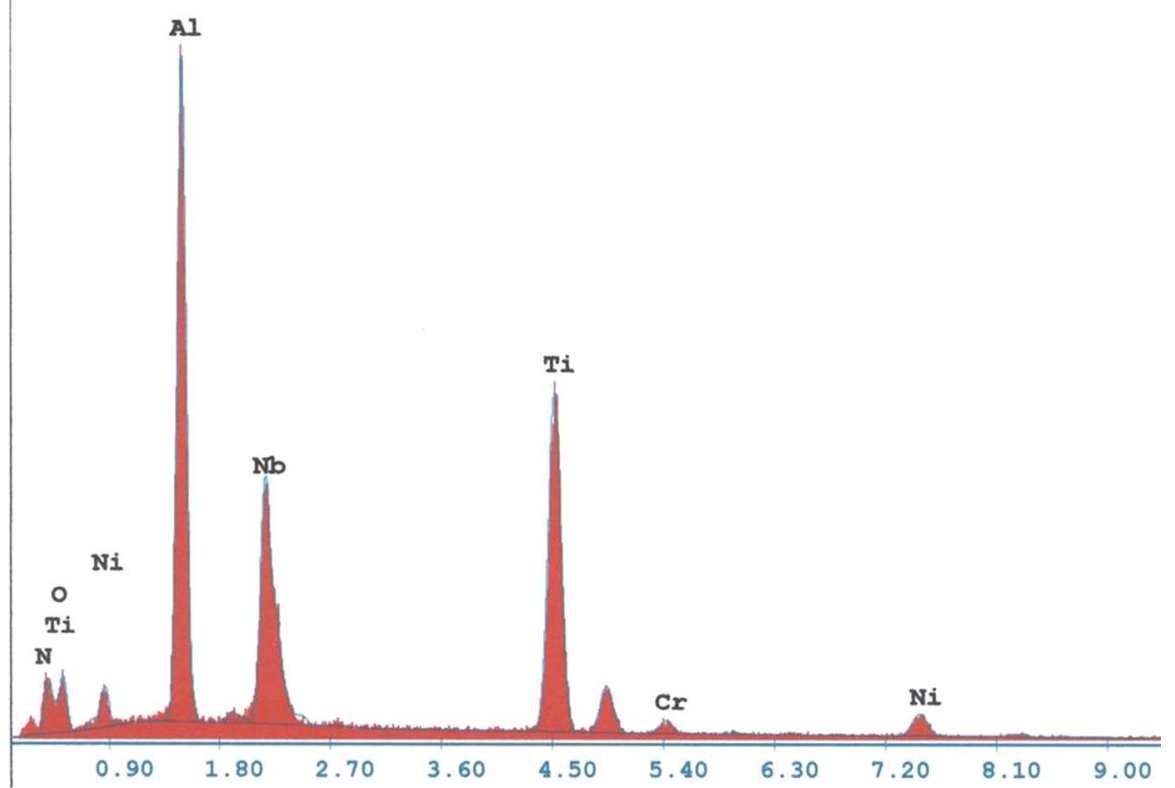

Fig. 4 (continued)

the product and the metallic substrate, a bright band enriched with niobium, chromium and nickel was observed (Fig. 4d). A detailed list of the quantitative chemical composition analysis is presented in Table 1 . 
Table 1 Results of microanalysis of chemical composition from areas marked in Fig. 3c (in the quantitative analysis, oxygen and nitrogen were not taken into account)

\begin{tabular}{lllllll}
\hline & Element & $\mathrm{Ti}$ & $\mathrm{Al}$ & $\mathrm{Nb}$ & $\mathrm{Cr}$ & $\mathrm{Ni}$ \\
\hline Chemical composition in point \# 1 & \%mas & 75.9 & 23.1 & - & - & - \\
& \%at & 64.0 & 34.6 & - & - & - \\
Chemical composition in point \# 2 & \%as & 43.3 & 50.0 & 6.7 & - & - \\
& \%at & 32.0 & 65.5 & 2.5 & - & - \\
Chemical composition in point \# 3 & \%mas & 73.1 & 17.1 & 9.8 & - & - \\
& \%at & 67.4 & 27.0 & 5.6 & - & - \\
Chemical composition in point \# 4 & \%mas & 44.5 & 25.2 & 26.1 & 1.3 & 2.9 \\
& \%at & 42.9 & 41.5 & 12.7 & 0.6 & 2.3 \\
\hline
\end{tabular}

Such observations regarding the construction of oxidation products were confirmed by the microanalysis of metallographic samples after oxidation also at lower temperatures. The layer structure and morphology of the products are essentially no different; however, it can be noticed that, with the increase in temperature in the area of the phase boundary, micropores develop more actively at the interface of the product-metallic substrate, which is associated with the increase of the oxidation temperature and definitely accelerates the diffusion processes in the oxidized layer and the metallic substrate (Fig. 3a-c).

$\mathrm{X}$-ray phase analysis results and diffraction patterns for $\mathrm{Ti}-46 \mathrm{Al}-7 \mathrm{Nb}$ alloy samples with oxidation products after annealing are presented in Figs. 5, 6 and 7.

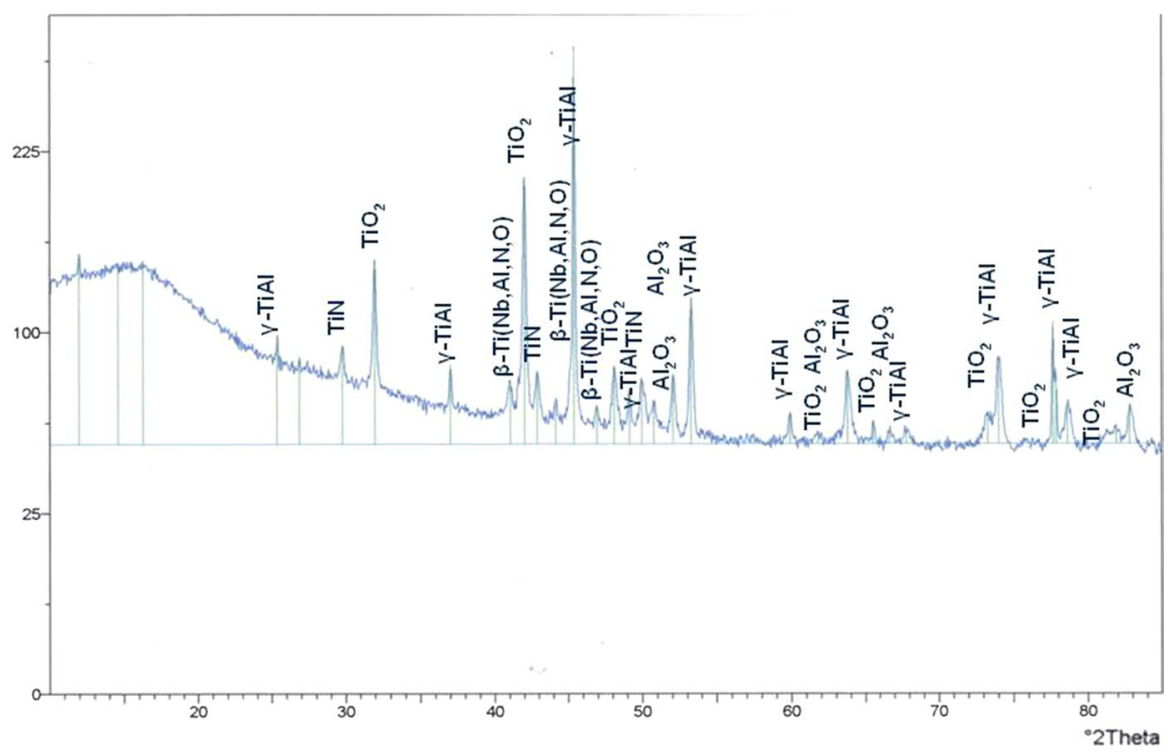

Fig. 5 X-ray diffraction pattern and X-ray phase analysis results of products formed during the oxidation of Ti-46Al-7 $\mathrm{Nb}$ in air at $875^{\circ} \mathrm{C}$, after removing the oxidation products layer 


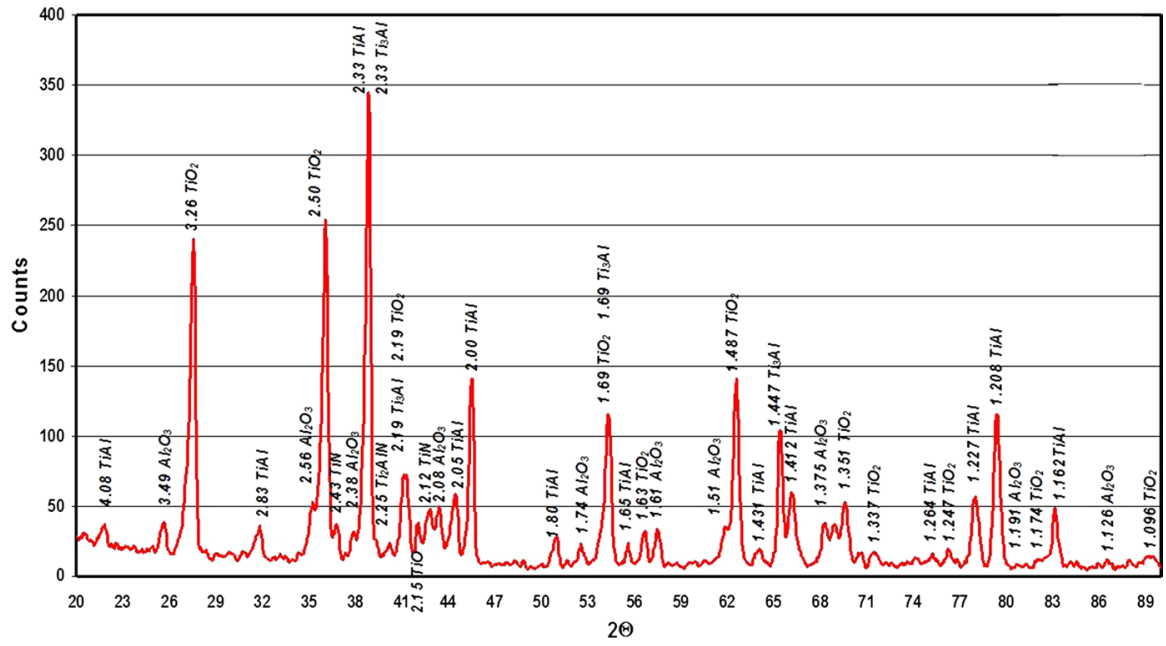

Fig. 6 X-ray diffraction pattern and X-ray phase analysis of products generated during oxidation of $\mathrm{Ti}-46 \mathrm{Al}-7 \mathrm{Nb}$ in air at $900{ }^{\circ} \mathrm{C}$

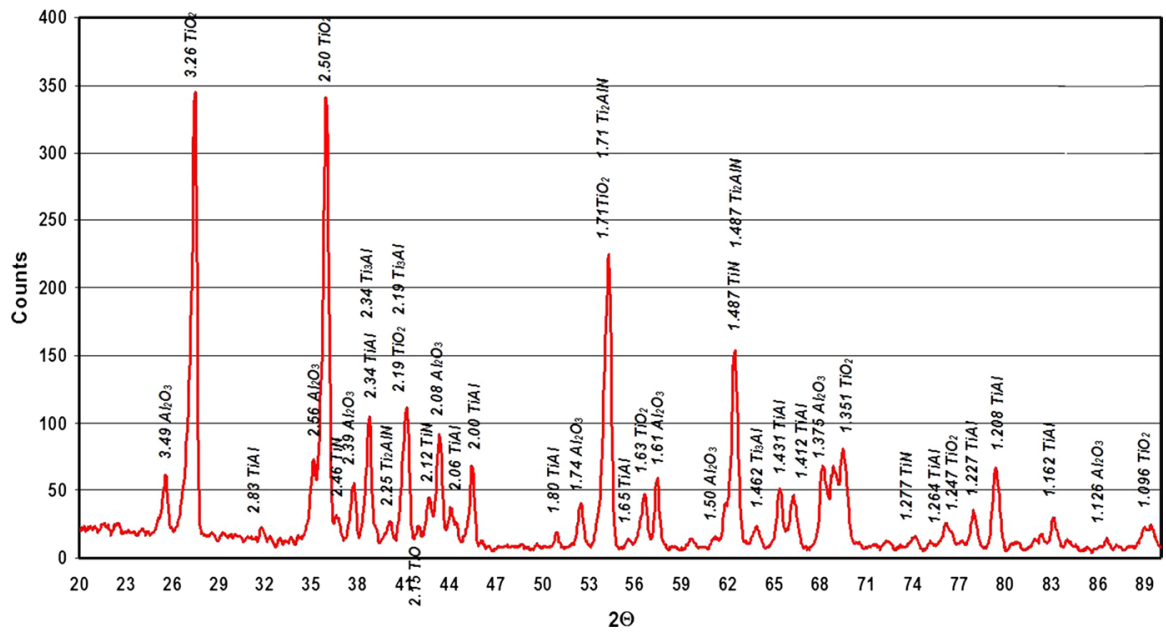

Fig. 7 X-ray diffraction pattern and X-ray phase analysis of products generated during oxidation of $\mathrm{Ti}-46 \mathrm{Al}-7 \mathrm{Nb}$ in air at $975^{\circ} \mathrm{C}$

The fact that the nucleating phase components are rutile $\mathrm{TiO}_{2}$ and $\mathrm{Al}_{2} \mathrm{O}_{3}$ is obvious. In addition to these basic oxides $\left(\mathrm{TiO}_{2}\right.$ and $\left.\mathrm{Al}_{2} \mathrm{O}_{3}\right)$, there are also nitrides ( $\mathrm{TiN}$, $\mathrm{Ti}_{2} \mathrm{AlN}$ ) and the metallic substrate phase, namely the intermetallic phase $\gamma$-TiAl. The explanation of this fact is easy. Under these oxidation conditions, the product formed is sufficiently thin (temperature $900{ }^{\circ} \mathrm{C}$ ), so the basic phase of the metallic substrate can insert its lines. At $950{ }^{\circ} \mathrm{C}$, the scale is already spalling, so here too, the $\gamma$-TiAl phase produces its lines. In order to obtain data regarding the phase composition 
directly at the metallic substrate, the scale was removed from the alloys oxidized at $875^{\circ} \mathrm{C}$ using the stress method (Fig. 5). The metal substrate has both nitrogen and oxygen. Such a composition of the substrate confirms that inward diffusion takes place of both these gaseous components of the oxidizing atmosphere.

\section{Discussion}

The analysis of the test results allows to state that the oxidation of the Ti-46Al-7Nb alloy does not only consist in the formation of scale, but also in the transformation in the metallic substrate. They are caused by the outward diffusion of alloying elements and formation phases and solid solutions by inward diffusion of $\mathrm{N}$ and $\mathrm{O}$. On the basis of the conducted tests, it can be concluded that the oxidation products consist of three sublayers, and in the metallic substrate a band rich in $\mathrm{Nb}$ is formed (Fig. 8).

During the oxidation of the tested $\mathrm{Ti}-46 \mathrm{Al}-7 \mathrm{Nb}$ alloy, it is not possible to form a continuous protective film $\mathrm{Al}_{2} \mathrm{O}_{3}$ on the surface since the external oxide sublayer always consists of $\mathrm{TiO}_{2}$. The reason for this is the main alloy component-titanium, which hinders the formation of a protective layer based on aluminum oxides. A characteristic feature of the rutile is that it may have two defective subnetworks: cationic and anionic, depending on the partial pressure of oxygen (Fig. 9). Therefore, the network diffusion in these alloys can develop in two directions. Through the defective anion sublattice, inward oxygen and nitrogen diffusion takes places, while the outward diffusion of metal ions occurs through the defective cationic sublattice. The energy of $\mathrm{Al}_{2} \mathrm{O}_{3}$ formation is more negative than the energy of $\mathrm{TiO}_{2}$ formation; [24] therefore, in the alloy in which the concentration of $\mathrm{Ti}$ and $\mathrm{Al}$ is the same, the $\mathrm{Al}_{2} \mathrm{O}_{3}$ layer "should" be formed (Fig. 10). The formation of layers, however, runs differently in these alloys. Titanium is oxidized to metastable oxides according to the homologous series $\operatorname{TinO}_{2 n-1}$ ( $\mathrm{TiO}, \mathrm{Ti}_{2} \mathrm{O}_{3}, \mathrm{Ti}_{3} \mathrm{O}_{5}, \mathrm{Ti}_{4} \mathrm{O}_{7}$ ) and to the stable $\mathrm{TiO}_{2}$ form. $\mathrm{TinO}_{2 n-1}$ oxides are characterized by equilibrium dissociation pressure close to that of $\mathrm{Al}_{2} \mathrm{O}_{3}$. The rate of growth of $\mathrm{TiO}$ and $\mathrm{Ti}_{2} \mathrm{O}_{3}$ is definitely higher than that of $\mathrm{Al}_{2} \mathrm{O}_{3}$ formation [25], and therefore, $\mathrm{TiO}$
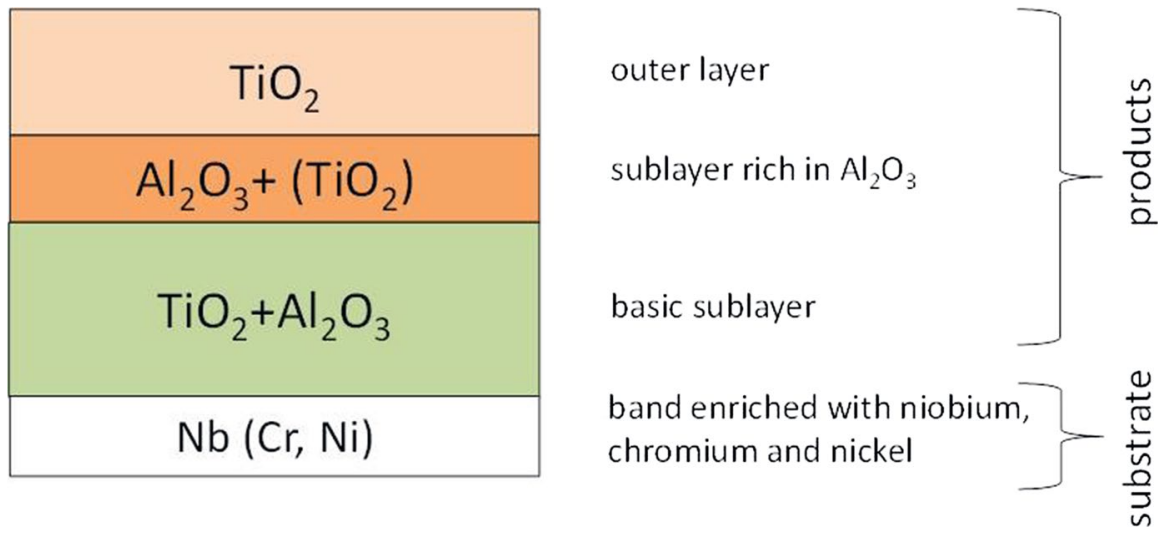

Fig. 8 Schematic diagram of the scale after oxidation of the Ti-46Al-7Nb alloy 


\section{Identification: $\mathrm{p}_{02}, \mathrm{~T}$}

- Kofstad's model

- Muracco's model

- Baumard's model

- Levin's and Rose's model $977-1227^{\circ} \mathrm{C}$

$800-1100^{\circ} \mathrm{C}$

$1140-1420^{\circ} \mathrm{C}$

$>1000^{\circ} \mathrm{C}$
$V_{0}{ }^{\prime \prime}$

$\mathrm{Ti}_{\mathrm{i}}{ }^{2000}\left(\mathrm{p}_{\mathrm{O} 2} \downarrow \ll \mathrm{T} \uparrow \mathrm{a}\right)$

$\mathrm{V}_{\mathrm{o}}^{*}\left(\mathrm{p}_{\mathrm{O} 2} \uparrow \underline{\mathrm{a}} \mathrm{T} \downarrow \ll\right)$

$\mathrm{Ti}_{\mathrm{i}}{ }^{0 \cdot}$

$\mathrm{Ti}_{\mathrm{i}}{ }^{200} \mathrm{i} \mathrm{Ti}_{\mathrm{i}}{ }^{n 000}$

Fig. 9 Dominating lattice defects in rutile

oxide is formed in the initial oxidation stage, and only then $\mathrm{Al}_{2} \mathrm{O}_{3}$. $\mathrm{TiO}_{2}$ is in direct contact with the hot air, which is transformed into $\mathrm{Ti}_{2} \mathrm{O}_{3}$, and then into rutile $\mathrm{TiO}_{2}$. (There is definitely higher partial pressure of oxygen.) Thus, as a result of the outward diffusion of titanium, a layer composed of rutile is formed. The formation of an external rutile layer results in a change in the balance of the $\mathrm{Ti}$ and $\mathrm{Al}$ quantitative contribution and, as a result of the slower diffusion of this element under the rutile layer, a mixed sublayer rich in $\mathrm{Al}_{2} \mathrm{O}_{3}$ is formed. The diffusing, titanium cations are transferred mostly to the surface. The formed $\mathrm{Al}_{2} \mathrm{O}_{3}$ layer is a heterogeneous layer, and it is not compact. It also includes, in smaller amounts, $\mathrm{TiO}_{2}$ rutile. The presence of rutile determines the

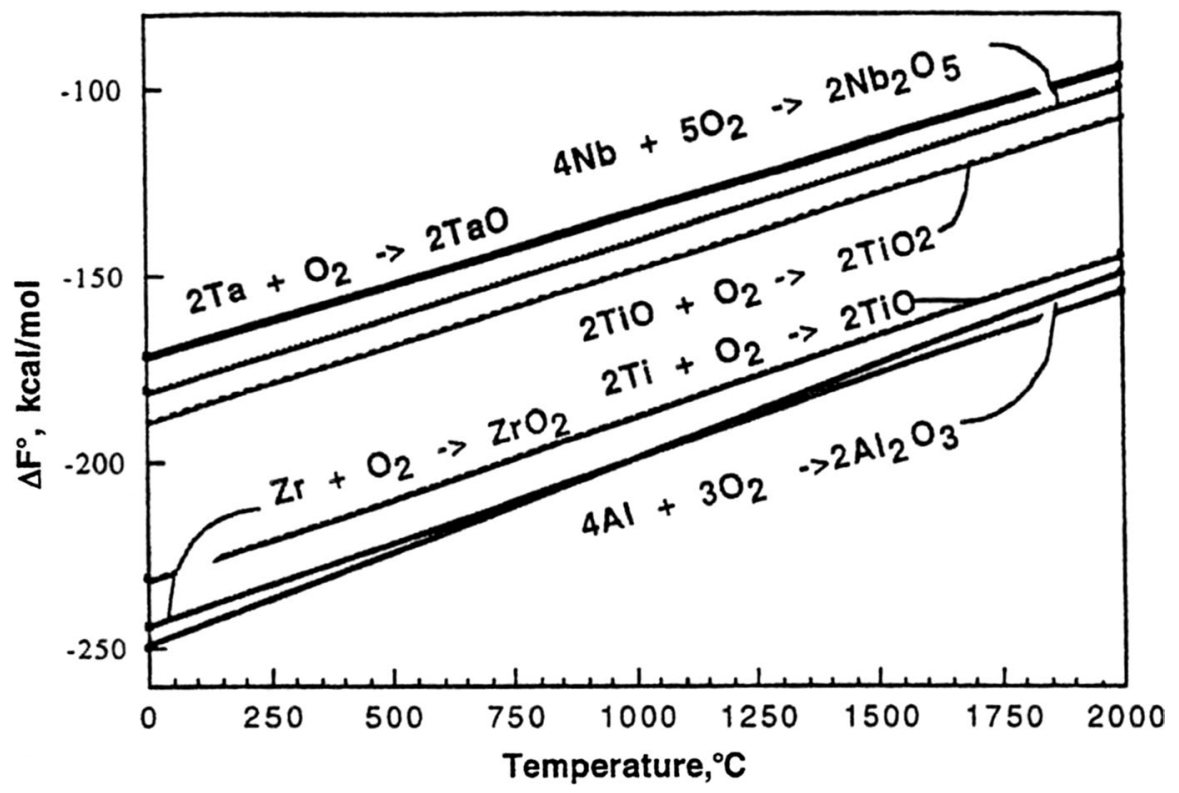

Fig. 10 The energy of formation of selected oxides $\left(\mathrm{Nb}_{2} \mathrm{O}_{5}, \mathrm{TaO}, \mathrm{TiO}_{2}, \mathrm{ZrO}_{2}, \mathrm{TiO}\right.$ and $\left.\mathrm{Al}_{2} \mathrm{O}_{3}\right)$ as a function of temperature [24] 
further course of the oxidation process. As already mentioned, rutile has a defective anion sublattice and inward oxygen diffusion takes place. Oxygen diffuses toward the product-metallic substrate interface, causing an increase in the thickness of the oxide layer as a result of the formation of titanium and aluminum oxides in this layer. The occurrence of defects in rutile depends on the partial pressure of oxygen. At a higher temperature, inward oxygen diffusion (through doubly and individually ionized oxygen vacancies of the rutile) takes place as well as outward diffusion of titanium, aluminum and elements contained in the alloy. In this way, a third mixed sublayer is formed, extending from a sublayer rich in $\mathrm{Al}_{2} \mathrm{O}_{3}$ to a metallic substrate. At a lower temperature, in rutile there are almost no defects in the cationic sublattice and inward diffusion of oxygen through the defective anion sublattice is limited. The higher temperature of the process also causes the growth of rutile crystals. Niobium does not diffuse simultaneously with $\mathrm{Al}$ and $\mathrm{Ti}$ in the outward direction, but stays in the metallic substrate, which increases its concentration, and therefore, in the area of the metallic substrate microbands rich in niobium are formed, producing light contrast in the BSE. As a result of this course of oxidation products formation, aluminum is depleted from the metallic substrate, and the substrate is enriched with nitrogen and oxygen. It is significant what phases, outside diffusion processes, are formed in the layer and how other alloying elements, as well as nitrogen and oxygen, will relate to these phases. Alloying additions such as $\mathrm{Nb}, \mathrm{Cr}, \mathrm{Ni}$ are elements that expand the range of the $\beta$-Ti phase and thus affect the solubility of nitrogen and oxygen by distinctly limiting it. In turn, aluminum, nitrogen and oxygen are alpha-forming elements, which means that oxygen and nitrogen have very good solubility in $\alpha$-Ti.

Since the studied corrosion tests of $\mathrm{Ti}-\mathrm{Al}$ alloys based on intermetallic phases most often concern temperatures above $800{ }^{\circ} \mathrm{C}$, and the theoretical conversion $\alpha$-Ti $\rightarrow \beta$-Ti takes place at the temperature of $882.5^{\circ} \mathrm{C}$, it is significant what phases are formed in the micro-layer subject to diffusion. It is possible that as a result of $\mathrm{Al}$ outward diffusion, the surface of the metallic substrate will contain:

- Phase $\alpha_{2}-\mathrm{Ti}_{3} \mathrm{Al}$ with dissolved oxygen and nitrogen,

- $\alpha$-Ti intermetallic phase with plenty of dissolved aluminum, oxygen and nitrogen,

- $\quad \beta$-Ti phase with a small amount of dissolved aluminum, oxygen and nitrogen, but with a big volume of $\beta$-forming elements.

In the 1990 s, reports appeared of a completely different phase (" $Z$ ' phase) that occurs during the oxidation of $\mathrm{Ti}-\mathrm{Al}$ alloys, rather than oxidation products and the phases of $\alpha_{2}-\mathrm{Ti}_{3} \mathrm{Al}$ and $\gamma$-TiAl. According to Zheng et al. [26], this phase is a compound with the composition $\mathrm{Ti}_{5} \mathrm{Al}_{3} \mathrm{O}_{2}$ and it is formed as a result of the reaction:

$$
5 \mathrm{TiAl}+2 \frac{1}{2} \mathrm{O}_{2}=\mathrm{Ti}_{5} \mathrm{Al}_{3} \mathrm{O}_{2}+\mathrm{Al}_{2} \mathrm{O}_{3}
$$

Accordingly, in alloys containing 44-52 at.\% of $\mathrm{Al}$ this reaction takes place under the $\mathrm{Al}_{2} \mathrm{O}_{3}$ scale. It is suggested that the stability of $\mathrm{Al}_{2} \mathrm{O}_{3}$ scale can occur only if it is separated from the metallic phase by a continuous " $Z$ ' phase film. The observation of the structure of the metal layer formed during oxidation near the scale 
indicated that it consisted of columnar grains located perpendicular to the phase boundary. It consists of alternating crystallites of the " $Z$ ' phase and the $\alpha_{2}-\mathrm{Ti}_{3} \mathrm{Al}$ phase. Therefore, the disappearance of the phase " $Z$ ' and formation of two-phase structure $\alpha_{2}+$ " $Z$ ' are not theoretically justified, so practically the " $Z$ ' phase does not affect the heat resistance of the alloy in any way. In the work of Copeland et al. [27], it was inferred that the phase ' $Z$ ' is an unstable phase, and its decay into $\alpha_{2}$ occurs when the oxidized metal supersaturates the metallic phase with simultaneous distinct reduction of the aluminum content. In many works assuming the existence of the ' $Z$ ' phase to constitute their hypothesis, it was claimed that providing good resistance of $\mathrm{TiAl}$ alloys, i.e., preventing the degradation of the $\mathrm{Al}_{2} \mathrm{O}_{3}$ sublayer, can be obtained by modifying the chemical composition that will enhance the stability of the continuous " $Z$ " phase [28, 29]. Expectations in this respect were, as it was believed, partially satisfied with the addition of copper. In $\gamma$-TiAl alloys, however, the more beneficial influence of copper on the increase in oxidation resistance was attributed to the influence of copper on the stabilization of the $\gamma$-TiAl phase [29-31]. However, the situation changed significantly when it was found that the introduction of high-melting metals, e.g., $\mathrm{Nb}$ in an amount of $5-10 \%$ significantly reduces the rate of oxidation [32-35]. At that time, many controversial explanations were proposed based on the effect of adding high-melting metals or creating oxides of high-melting metals mixed with $\mathrm{TiO}_{2}$ and $\mathrm{Al}_{2} \mathrm{O}_{3}$ and "gluing" grains in the scale with the elimination of three-dimensional defects [35]. Another explanation is based on nitrogen removal in $\mathrm{Ti}-\mathrm{Al}$ alloys, with the addition of $\mathrm{Nb}$, consisting in the formation of TiN and AlN at the metal-scale interface, which causes "sealing" of the intergranular boundaries in the $\mathrm{TiO}_{2}+\mathrm{Al}_{2} \mathrm{O}_{3}$ scale, thus reducing the volume of inward diffusion of oxygen $[36,37]$. In recent years, literature reports about the " $Z$ ' phase have almost completely disappeared. Doubts about the existence of this phase were aroused due to the fact that there have been no structural characteristics of cell structure, network constants or atom distribution. The finding that the " $Z$ ' phase occurs in the metallic substrate directly adjacent to the oxidation products is based on EDS analysis (composition close to $\mathrm{Ti}_{50} \mathrm{Al}_{30} \mathrm{O}_{20}$ [38]) and not on X-ray structural analysis.

So, with a large number of $\alpha$-forming elements, after significant amounts of aluminum diffused outward from the metallic substrate, there will be no intermetallic phases from the $\mathrm{Ti}-\mathrm{Al}$ system $\left(\mathrm{Ti}_{3} \mathrm{Al}, \mathrm{TiAl}\right)$ but the $\alpha$-Ti phase enriched with $\alpha$-forming oxygen and nitrogen. The high solubility of these elements in $\alpha$-Ti (Al, $\mathrm{N}, \mathrm{O}$ ) may make the oxide layer expand by excessive oxygen saturation. In the case of the analyzed alloy containing a large number of $\beta$-forming elements $(\mathrm{Nb})$, the aluminum outward diffusion changes the chemical composition in a thin metallic sublayer, but the $\beta$-Ti phase $(\mathrm{Nb}, \mathrm{Al}, \mathrm{O}, \mathrm{N})$ with a small volume of dissolved oxygen and nitrogen will dominate at the oxidation temperature (Fig. 5). These results are justified in the $\mathrm{Ti}-\mathrm{Al}-\mathrm{Nb}$ system, from which it follows that the reduction in $\mathrm{Al}$ leads to the formation of a wide area of $\beta$ solid solution [39]. The lack of the possibility of a significant dissolution of oxygen in this solution caused that, at high temperature, with extending the oxidation time, this thin sublayer undergoes fragmentation into bands of the solid $\beta$ - Ti $(\mathrm{Nb})$ perpendicular to the surface of the alloy interspersed with the bands of $\mathrm{TiO}_{2}+\mathrm{Al}_{2} \mathrm{O}_{3}$ oxides. During the oxidation, in these 
oxide bands, only the $\alpha$-Ti phase (Al, N, O) could originally be present, which transformed into an oxide one after oxygen saturation.

\section{Conclusions}

1. Due to high temperature on the surface, the layer of reaction products is formed as a result of the diffusion exchange between the components of the alloy, which leads to considerable changes in the composition of materials and the layer near to metallic substrate.

2. It was found that the oxidation process consists of two main processes:

- The process of oxidation product development (scale).

- The creation of solid solution of oxygen/nitrogen in sublayers of metallic substrate immediately adjacent to the oxidation product,

3. Oxide layers formed as a result of high-temperature oxidation of the $\mathrm{Ti}-\mathrm{Al}-\mathrm{Nb}$ alloy are composed of several specific sublayers:

- External sublayer consisting predominantly of the rutile depositions containing also oxides of $\mathrm{Al}$,

- Central sublayer forming a band running parallel to the oxide surface and characterized by the presence of dominant volumes of $\mathrm{Al}_{2} \mathrm{O}_{3}$ and $\mathrm{TiO}_{2}$ to a lesser degree,

- Inner sublayer containing comparable amounts of $\mathrm{Al}_{2} \mathrm{O}_{3}$ and $\mathrm{TiO}_{2}$.

OpenAccess This article is distributed under the terms of the Creative Commons Attribution 4.0 International License (http://creativecommons.org/licenses/by/4.0/), which permits unrestricted use, distribution, and reproduction in any medium, provided you give appropriate credit to the original author(s) and the source, provide a link to the Creative Commons license, and indicate if changes were made.

\section{References}

1. A. Bylica and J. Sieniawski, Titanium and it's alloys (PWN Warsaw, 1985).

2. ASM Handbook, Alloy Phase Diagrams, Metal Treatment, Structure and Joining Collection, Section: Binary Alloy Phase Diagrams-Standard Content, Vol. 3 (1998).

3. EA. Loria, Intermetallics 8, 13 (2000).

4. C. M. Ward-Close, R. Minor and P. J. Doobar, Intermetallics 4, 217 (1996).

5. F. Appel, M. Oehring and R. Wagner R, Intermetallics 8, 1283-1312 (2000).

6. Y. Wu, K. Hagihara and Y Umakoshi, Intermetallics 13, 879 (2005).

7. B. G. Kim, G. M. Kim and C. J. Kim, Scripta Metallurgica et Materialia, 33, 1117 (1995).

8. J. L. Murray, International Metals Reviews 30, 211 (1985).

9. I. Ohruma, Y. Fujita, H. Mitsui, K. Ishikawa, R. Kainuma and K. Ishida, Acta Materialia 48, 3113 (2000).

10. Inorganic Crystal Structure Database, National Institute of Standards and technology (U.S. Department of Commers, 2005).

11. G. Moskal, Journal of Achievements in Materials and Manufacturing Engineering 22, 31 (2007).

12. M. Góral, G. Moskal and L. Swadźba, Journal of Achievements in Materials and Manufacturing Engineering 20, 443 (2007). 
13. G. Moskal, Journal of Achievements in Materials and Manufacturing Engineering 20, 263 (2007).

14. M. Yoshihara and Y. W. Kim, Intermetallics 13, 952 (2005).

15. V. Shmet, M. Yurechko, A. K. Tyagi, W. J. Quadakkers and L. Singheiser, in The influence of Nb and $\mathrm{Zr}$ additions on the high temperature oxidation mechanism of $\gamma$-TiAl alloys in Ar/O $\mathrm{O}_{2}$, eds. Y.-W. Kim, D. M. Dimiduk and M. H. Loretto (The Minerals, Metals \& Materials Society, Pittsburgh, 1999), p.783.

16. L. Huang, P. K. Liaw and C. T. Liu, Microstructural Evolution of TiAl-Intermetallic Alloys Containing Tungsten and Boron. in Proceedings paper, Session II (Oak Ridge National Laboratory, Managed by UT Battelle for the Department of Energy, 2005).

17. N. Toshio, I. Takeshi, M. Yatagai and T. Yoshioka, Intermetallics 8, 371 (2000).

18. M. Góral, G. Moskal and L. Swadźba, Journal of of Achievements in Materials and Manufacturing Engineering 18, 459 (2006).

19. M. Góral, G. Moskal, L. Swadźba and T. Tetsui, Journal of Achievements in Materials and Manufacturing Engineering 21, 75 (2007).

20. S. Król and A. Zalisz, Oxygen Diffusion in Titanium and its Abrasive Wear. 10th World Conference on Titanium, Hamburg, in Ti-2003 Science and Technology, eds. G. Luetjering, Vol. III (2003), p. 1699.

21. T. Jungling and R. A. Rapp, Metallurgical and Materials Transactions 134A, 929 (1982).

22. L. Matson, H. Erhart, M. Lee and R. A. Rapp, Metallurgical and Materials Transactions 15A, 2241 (1984).

23. G. M. Reynaud, W. A. T. Clark and R. A. Rapp, Metallurgical and Materials Transactions 15A, 573 (1984).

24. J. C. Woo, S. K. Varma and R. N. Mahapatra, Metallurgical and Materials Transitions A 34A, 2263 (2003).

25. F. N. Rhines and J. S. Wolf, Metallurgical Transactions 1, 1701 (1970).

26. N. Zheng, W. Fischer, H. Grubmeier, V. Shemet and W. I. Quadakkers, Scripta Metallurgia et Materialia 33, 47 (1995).

27. E. H. Copland, B. Gleeson and D. J. Young, Acta Materialia 10, 2937 (1999).

28. V. Shemet, P. Karduck, H. Hoven, B. Grushko B, W. Fischer and W. J. Quadakkers, Intermetallics 5, 271 (1997).

29. A. Gil, L. Niewolak, A. Czyrska-Filemonowicz, H. J. Penkalla, V. Shemet, L. Singheiser and W. J. Quadakkers, Materials Engineering 4, 341 (2001).

30. V. Shemet, A. K. Tyagi, H. J. Penkalla, L. Singheiser, J. S. Becker and W. J. Quadakkers, Materials at High Temperatures 17, 41 (2000).

31. L. Singheiser, W. J. Quadakkers and V. Shemet, in Gamma Titanium Aluminides, eds. Y. W. Kim, H. Clemens and A. H. Rosenberg (The Minerals, Metals and Materials Society, Pittsburgh, 2003), p. 585.

32. S. Taniguchi and T. Shibata, Intermetallics 4, 85 (1996).

33. V. A. C. Haanappel, H. Clemens and M. F. Stroosnijder, Intermetallics 10, 293 (2002).

34. J. W. Fergus, Material Science and Engineering A338, 108 (2002).

35. G. Welsch and A. I. Kahveci, in Oxidation of High Temperature Intermetallics, eds. T. Grobstein and J. Doychak (The Minerals, Metals and Materialsd Society, 1998), p. 207.

36. N. Zheng, W. J. Quadakkers, A. Gil and H. Nickel, Oxidation of Metals 44, 477 (1995).

37. W. J. Quadakkers, P. Schaaf, N. Zheng, A. Gil and E. Wallura, Materials and Corrosion 48, 28 (1997).

38. L. Singheiser, W. J. Quadakkers and V. Shemet, in Gamma Titanium Aluminides, eds. Y. W. Kim, D. N. M. Dimiduk and M. H. Loretto (The Minerals, Metals and Materials Society, Pittsburgh, 1999), p. 743 .

39. A. Hellwig, M. Palm and G. Inden, Intermetallics 6, 79 (1988). 